\title{
OS JOGOS TEATRAIS DE VIOLA SPOLIN COMO POSSIBILIDADE DE CONTAR HISTÓRIAS COM/NO CORPO PARA PROFESSORES
}

\section{Theater games of Viola Spolin as a possibility to tell stories with/in the body for teachers}

\author{
Valquíria Duarte \\ Universidade Federal de Goiás - UFG
}

Resumo: O presente artigo aborda a contação de histórias e suas possíveis relações com os jogos teatrais de Viola Spolin, tendo como eixo central a experiência que obtive por meio de oficinas de contação de histórias que ministrei e foram ofertadas para professores da Rede Municipal de Educação, em Goiânia, nos anos de 2017 e 2018.

Palavras-chave: Contação de história; Jogos teatrais; Professores.

Abstract: This article discusses storytelling and its possible relations with the Viola Spolin's theatrical games, having as a central axis being the experience I obtained through storytelling workshops offered to teachers from the Municipal Education Network in Goiânia in the years 2017 and 2018.

Keywords: History Counting; Theater plays; Workshop. 
O presente escrito parte da minha experiência em contar histórias com/no corpo, como professora de teatro e contadora de histórias, bem como ministrante de oficinas de contação de histórias ofertadas para professores da Rede Municipal de Educação, em Goiânia, nos anos de 2017 e 2018. Estas oficinas tinham o objetivo de potencializar o contar histórias dos participantes por meio do corpo. Potencializar o contar, neste caso, ganha o sentido de potencializar a expressão corporal, expressão que se constitui de gestos: gestos de rosto (olhar e mímica); gestos de membros superiores, da cabeça, do busto; gestos do corpo inteiro e da voz.

Diante a este objetivo, surgiram-me inquietações a respeito de investigar possibilidades em contar histórias com o foco na corporeidade do professor/contador de histórias. Frente a seguinte indagação: como desenvolver uma oficina em contação de histórias com professores, de forma a instigar sua corporeidade em consonância com a sua prática pedagógica?

Cabe ressaltar que contar histórias com e no corpo é uma proposta desafiadora de perceber o corpo como foco principal no contar histórias, pois é por meio dele que conto, independente dos objetos que utilizo ou não durante a contação, um corpo presente, vivo e ampliado.

Ademais, pude perceber, nas oficinas que ministrei, a dificuldade de muitos professores em se movimentar e expressar-se corporalmente. Em sua maioria, os professores tinham dificuldade em ficar descalços, sentar em círculo, no chão, criar movimentos extracotidianos e brincar corporalmente.

Esta realidade me fez refletir sobre a importância de oferecer a estes professores uma proposta voltada para brincadeiras e jogos teatrais como forma de oportunizar novas experiências corporais, lembrando-os de que se tem um corpo e, com ele, podemos descobrir muitas coisas, inclusive, um jeito particular de contar histórias.

Desse modo, desenvolvi nos anos de 2017 e 2018 oficinas de contação de histórias, com duração de quatro horas, para professores da Rede Municipal de Educação de Goiânia, tendo como proposta a vivência de alongamento corporal e aquecimento vocal, brincadeiras cantadas e jogos teatrais de Viola Spolin 
baseados nos livros: Improvisação para o teatro (2005) e O fichário de Viola Spolin (2001).

No que se diz respeito ao alongamento corporal e ao aquecimento vocal, eram os primeiros exercícios feitos nas oficinas, e foram divididos em: cabeça, tronco e membros superiores e inferiores. Durante as oficinas que ministrei pude perceber que, ao alongar o corpo, os professores entravam em contato consigo mesmos, despertando sua sensibilidade corporal, descobrindo suas potencialidades e flexibilidades.

Já os aquecimentos vocais, além de prepararem a voz para os jogos e as improvisações de histórias, também contribuíram para a projeção e articulação das palavras ditas, como também para a expressão facial dos professores participantes.

Referente às brincadeiras cantadas, entendo como uma brincadeira que pode ser executada em roda e ministrada por um propositor que utiliza seu corpo como um brinquedo e que, por meio de gestos e música, brinca consigo e com os outros participantes, que o imitam em tudo que faz. Os gestos ofertados durante a execução da brincadeira cantada partem da corporeidade do propositor, estes gestos deverão estar em consonância com a música cantada.

Embora as brincadeiras cantadas não sejam instituídas como uma técnica, utilizei-as como tal nas oficinas de contação de histórias e procurei explorar, nessas brincadeiras, movimentos e gestos que possibilitassem ao máximo a expressão corporal dos professores participantes, sendo que, muitas vezes, estas brincadeiras eram mais encenadas do que cantadas. O que resultava em corpos brincantes despertos e na produção de energia necessária para a vivência dos jogos teatrais.

Quando me reporto a jogos teatrais, estou partindo dos jogos desenvolvidos por Viola Spolin (2001, 2005), escritora norte-americana que, em 1963, sistematizou, pela primeira vez, seus estudos sobre os jogos teatrais em seu livro "Improvisação para o Teatro", publicado nos Estados Unidos, no qual propõe os jogos teatrais "como caminho possível para o trabalho teatral" (RAMALDES e CAMARGO, 2017, p. 25). 
Assim, a autora propõe jogos que estimulam a descoberta, a experiência e a expressão criativa, bem como, direcionamentos para se jogar os jogos teatrais, que possibilitam aos jogadores se desprenderem de julgamentos de aprovação/desaprovação, adentrando no jogo teatral com amplitude e vitalidade, reverberando em uma experiência significativa em termos de espontaneidade, organicidade e resposta intuitiva, o que, de fato, foi ao encontro dos objetivos da oficina de contação de histórias que ofertei para os professores da Rede Municipal de Educação de Goiânia.

Ressalto então alguns dos direcionamentos propostos por SPOLIN (2001) (2005) e proponho uma possível correlação dos mesmos com o contar histórias e a prática pedagógica.

No que se diz respeito ao formato palco/plateia, proposto em alguns jogos teatrais, ressalto que a plateia também é um elemento fundamental na contação de histórias. Porém, em se tratando de adultos professores, este formato, durante as oficinas, foi inserido com cautela para não engessar os professores/jogadores que demonstravam receio de conceitos como aprovação/desaprovação da plateia.

De acordo com Ramaldes e Camargo (2017), "os jogos teatrais no formato palco e plateia, em que todos os jogadores passam pela mesma posição, a de observador e atuante, permitem a eles uma visão geral do desenvolvimento cênico" (p. 163). Esta explanação dos autores, a respeito do formato palco e plateia nos jogos teatrais, me remetem a um movimento circular, em que ora atuo, ora observo, experimentando diferentes posições, atuar/observar.

Constatei que, durante a vivência dos jogos teatrais propostos nas oficinas, os professores, ao observarem o colega no palco, se sentiam também capazes de ir ao palco no jogo proposto, despertando o desejo de estar em cena e de observar a mesma cena feita por outros colegas, só que realizada com um outro olhar, de uma outra forma. Ampliavam possivelmente sua visão crítica e criativa, observando e propondo diferentes formas de apresentar uma mesma história.

Ademais, durante as oficinas de contação de histórias, foi proposto o jogo "Exposição", que detalho como: "vocês olham para nós. Nós olhamos para vocês."

${ }^{1}$ Jogo retirado da ficha A1, O fichário de Viola Spolin (2001).

João Pessoa, V. 11 N. 2 jul-dez/2020

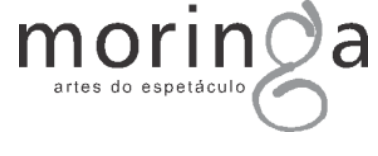


(SPOLIN, 2005, p. 47). Utilizado para potencializar o olhar dos professores e a importância do olhar no contar histórias.

Neste jogo, a turma de professores participantes era dividida em dois grupos enfileirados, um grupo ficava em pé e o outro grupo sentado. Quem ficava em pé era observado por quem estava sentado. Depois de um tempo, trocavam-se as posições. Em um dado momento, foi orientado para cada grupo uma ação a ser expressa apenas com o olhar, e o grupo que estivesse sentado falaria qual era a ação.

Para Spolin (2005), esse jogo possibilita a reflexão dos jogadores sobre o que tem para fazer no palco. "Essa alguma coisa para fazer" permite ao ator receber o ambiente (p. 48).

Visto isso, durante a avaliação do jogo, era percebido pelos participantes da oficina que, para estarem em cena, era necessário um foco, algo a expressar, e isso se evidenciava no corpo. Assim como na contação de histórias, quando se vai contar algo, a postura do corpo muda, o corpo fica em estado de alerta, cria-se uma energia. $\mathrm{O}$ corpo desperto, sabendo o foco que tem a ser atingido, gera energia e dá confiança ao contador de histórias.

Além disso, proporcionava aos professores refletir sobre a importância do olhar na contação de histórias. Nesta perspectiva, Lacombe (2015), em Quanta história numa história: relatos das experiências de uma contadora de histórias, afirma que "é preciso ver seu público. É preciso 'varrer' a plateia com o olhar. Quando olhamos, é como se estivéssemos trazendo cada um para o nosso colo. Fisicamente, isso não é possível, mas, com o olhar, conseguimos acalentar todo mundo" (p. 65).

Lacombe (2015) ressalta que o olhar expressivo também conta histórias, é por meio do olhar que o contador de história traz a plateia para si, para sua história. Olhar no olho do outro é reconhecer que existe alguém ali e que ele não está despercebido na multidão, demonstra ato de respeito e partilha de momento, história e sentimentos.

Durante as oficinas que ministrei, usava a expressão "lamber" em vez de "varrer", proferida pela autora (2015). Dizia aos professores que o contador de 
histórias tem que "lamber" a plateia com o olhar, de modo que todos sejam vistos. Olho no olho. O lamber de que estava falando era no sentido animal, o animal que lambe todo o filhote como forma de carinho e reconhecimento. $\mathrm{Na}$ escola, a troca de olhares entre professor e aluno é fundamental, como forma de parceria e confiança. O olhar expressivo do professor chama o aluno para o jogo da aprendizagem.

Ressalto que o jogo teatral não necessariamente exige o olhar para a plateia, porém, no caso das oficinas que ministrei para os professores, trabalhei mais com os jogos teatrais que direcionam o olhar para a plateia, pois se trata de uma característica forte da contação de histórias.

Um termo bastante utilizado por SPOLIN $(2001,2005)$ nos jogos teatrais é a fisicalização. Fisicalizar expressa a linguagem física da cena, transcende o campo das ideias para o físico: olhar, voz e gestos. Como nos mostram Karine Ramaldes e Robson Corrêa de Camargo (2017), em Os Jogos teatrais de Viola Spolin (Uma pedagogia da Experiência):

Fisicalizar, para Viola Spolin, é transformar em concreto o imaginário, é transpor para o corpo o que está no campo subjetivo, corporificar a "verdade cênica" orgânica, intuitiva de Stanislavski. Ao exercitar a fisicalização em cena, os educandos/jogadores trabalham a verdade cênica no jogo e descobrem a capacidade expressiva de seus corpos sem utilização de qualquer adereço de apoio. (2017, p. 158)

Este recorte teórico, a respeito da fisicalização de Spolin, demonstra aspectos que colaboraram para a construção da concepção de contar histórias com e no corpo, adotada nas oficinas de contação de histórias que ministrei. Tal concepção compreende o corpo como um todo expressivo e comunicativo cujos gestos e voz expressam e comunicam o modo sensível do contador de histórias de sentir e relacionar com o mundo.

Na contação de histórias, o imaginário é fisicalizado e vivificado no corpo do contador. Por isso, na aplicação dos jogos teatrais, durante as oficinas de contação de histórias, a fisicalização esteve sempre presente, como forma de viabilizar a 
organicidade de gestos e instigar a expressão corporal dos professores participantes.

Nesta perspectiva, ao falar de contar histórias com e no corpo, tomo o gesto do contador de histórias em paridade com a palavra dita, pois o gesto é repleto de significações, como ressalta Pereira (2010):

[...] ele, o gesto, responde ao paulatino distanciamento entre a experiência e a sua representação na linguagem, entre representação material e representação conceitual; responde a um processo histórico de desmaterialização do mundo, de modernização dos sentidos. (2010, p. 557-558)

Um exemplo que ilustra essa passagem é quando o contador de histórias faz a ação de pegar o prato, levar a comida até a boca e mastigar, por meio do gesto. Ele não necessita de fato ter um prato, garfo ou comida, ele representa esses materiais por meio dos gestos, deixando a imaginação do ouvinte fluir e decidir como é o formato do prato, sua cor...

Durante a vivência dos jogos teatrais nas oficinas de contação de histórias, procurava enfatizar aos professores esta importância dos gestos na história, pois tão importante como conhecer a história a ser contada, é perceber e ter ciência dos gestos que se exprimem durante o contar histórias.

O intuito de propor a vivência da fisicalização nos jogos teatrais, durante as oficinas de contação de história, era sensibilizar os professores participantes para o fato de que se contam histórias não só com palavras, mas com gestos do corpo todo, pois percebo a importância de contar histórias com e no corpo como forma de aguçar a imaginação do ouvinte, não ofertando materiais concretos, prontos ao contar.

Essa compreensão sobre o gesto em paridade com a palavra dita no contar histórias é ressaltada na fala de Letícia Erdtmann (2017), em seu texto O corpo como território - ancoragem e relevo para uma narrativa:

[...] um gesto é sempre o gesto daquele corpo em particular, mas porque ele literalmente divide com a palavra a responsabilidade da narrativa. Não ilustra, mas "toma a palavra" constantemente, 
continuando a contar a história [com acompanhamento da palavra dita, ou em silêncio]. Logo a seguir a história pode ser retomada pela palavra sem movimento corporal visível e assim sucessivamente. [...] Este "toma a palavra" é apenas uma metáfora no sentido de garantir uma imagem de continuidade que se verifica no trabalho, há um trânsito livre entre a palavra dita e as imagens corporais criadas. Não significa que as imagens corporais venham substituir a palavra, por vezes podem criar paisagens, dinâmicas ligadas às sensações provocadas pela história, criando um discurso visual paralelo. (2017, p. 181-182)

A autora ressalta que o gesto (gestos do corpo inteiro) é intrínseco do contar, visto que ele parte de dentro do corpo, no corpo e não como um recurso complementar. Dessa maneira, ele, o gesto, possibilita a criação de imagens corporais que expressam e contam história, construindo uma dinâmica contínua entre a palavra e o gesto. Os gestos expressos durante o contar histórias propiciam um discurso visual paralelo às palavras ditas e potencializam as sensações que a história contada oferece.

Ao que se refere à afirmação de Spolin (2005), a qual concebe que todas as pessoas são capazes de atuar no palco, vai ao encontro da concepção de contar histórias, da oficina, pois parte em perceber que todas as pessoas contam histórias, visto que o contador de histórias é aquele que ordena e organiza a experiência com o propósito de dar sentido ao vivido, ou seja, o ser humano faz isto em grande parte do seu tempo, como forma de se expressar, de comunicar e de se entender. Como argumenta Augusto Pessoa (2015), em Teatro e contação de histórias:

Não há necessidade de ter o dom, pois essa é uma prática inerente ao ser humano, uma vez que contamos histórias o tempo todo: relatamos o que aconteceu durante o dia ao chegar à noite em casa; narramos um filme, um livro ou uma novela que nos emociona de alguma forma etc. É a emoção que nos move como contadores de histórias. Tudo por causa da paixão, seja ela como for, torna-se parte do nosso repertório como narradores. (2015, p. 329)

Pessoa (2015) afirma que, quando uma história nos toca, nos emociona ou nos encanta, logo queremos compartilhá-la com o outro, e assim contamos e construímos o nosso repertório de histórias contadas e partilhadas. O sentimento, 
a socialização, a comunicação são inerentes ao ser humano e fazem parte do contar histórias.

Em se tratando das oficinas de contação de histórias, em seu relacionamento com o jogo teatral, se propicia ao professor descobrir-se como contador e jogador de histórias, por meio dos jogos teatrais. Isto proporciona um novo olhar às suas práticas pedagógicas, onde a sala de aula pode ser vista como um local de jogo e experimento, contribuindo assim, para o jogo professor-aluno em favor da construção colaborativa de uma aprendizagem significativa.

Percebo que experiências como estas estimulam os professores a experimentarem práticas pedagógicas brincantes, em que o corpo está vivo, expressivo e aberto ao jogo de ensinar e aprender. Vivências que possibilitam ampliar e inovar seu cotidiano como professor.

Para melhor entendimento, cito um trecho do livro Quem educa quem?, escrito por Fanny Abramovich (1985), o qual ressalta sobre:

[...] a importância de se vivenciar as coisas e não apenas ser informado sobre elas [...] Mas permitir ao aluno-professor que passe por todos os passos do seu próprio processo criativo.

É nessa caminhada vivida, sofrida, inquieta, sorridente, reveladora que ele, o aluno-professor, vai poder constatar aonde estão as impotências, o se deparar com o não saber como resolver algo que tinha proposto, a frustração perante o realizado, a dificuldade com o grupo junto ao qual está fazendo esta ou aquela atividade, a perplexidade perante o processo, a sua dificuldade em se autoavaliar, enfim, tudo o que acontece quando um ato criativo está em andança. (1985, p. 48)

É neste contexto descrito pela autora que surgiu a concepção das oficinas de contação de histórias, de forma a não oferecer receitas prontas de como contar histórias, mas propor que professores participantes experienciassem, vivenciassem e sentissem todo o processo criativo de contar histórias com e no corpo.

Desse modo, concluo que, ao proporcionar aos professores diferentes experimentações de possibilidades corporais, explorando e vivenciado o corpo no espaço, suas gestualidades em situação de jogos teatrais de Viola SPOLIN (2001) (2005), criou-se um lugar de pesquisa e possibilidades de troca e reflexão consigo 
e com o outro, onde foram exploradas diferentes maneiras de se contar/jogar histórias.

As oficinas de contação de histórias para os professores da Rede Municipal de Educação de Goiânia foram uma mola propulsora para potencializar o contador de história existente em cada professor participante. Experimentando, brincando, jogando, contando histórias, refletimos sobre saberes e aprendizagens. E, assim, enfatizar a importância de propor experiências como esta, de contar histórias com/no corpo no âmbito escolar, como proposta de inovação nas práticas pedagógicas.

Ressalto que não tenho o intuito de promover verdades absolutas, o meu interesse neste escrito foi o de suscitar, analisar e registrar as contribuições dos jogos teatrais de Spolin na prática de contar histórias com/no corpo para professores, enfatizando a importância do corpo no processo de ensinoaprendizagem, a construção colaborativa do saber entre professor e educandos, as vivências em processos criativos, visando transformar o espaço escolar em um lugar de experimento e criação.

Recebido em 06/09/2019

Aceito em 17/05/2020

\section{Referências}

ABRAMOVICH, Fanny. Quem educa quem? São Paulo: Summus, 1985.

ERDTMANN, Letícia Liesenfeld. O corpo como território - ancoragem e relevo para uma narrativa. In: TIERNO, Giuliano; ERDTMANN, Leticia Liesenfeld (Org.). Narrate cidade: pensamentos sobre a arte de contar histórias hoje. São Paulo: A Casa Tombada, 2017.

LACOMBE, Ana Luísa. Quanta história numa história: relatos das experiências de uma contadora de histórias. São Paulo: É Realizações, 2015.

PEREIRA, Marcelo de Andrade. A dimensão performativa do gesto na prática docente. Revista Brasileira de Educação - Revista Eletrônica, v. 15, n. 45, p. 555562, set./dez. 2010.

PESSOA, Augusto. Teatro e contação de histórias. In: MEDEIROS, Fábio Henrique Nunes; MORAES, Taíza Mara Rauen (Org.). Contação de histórias: tradição, poética e interfaces. São Paulo: Edições Sesc, 2015. 
RAMALDES, Karine; CAMARGO, Robson Corrêa de. Os Jogos teatrais de Viola Spolin (Uma pedagogia da Experiência). Goiânia: Kelps, 2017.

SPOLIN, Viola. Improvisação para o teatro. 5. ed. São Paulo: Perspectiva, 2005. SPOLIN, Viola. Jogos Teatrais: o fichário de Viola Spolin. São Paulo: Perspectiva, 2001. 